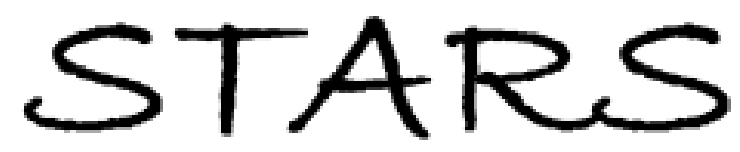

University of Central Florida

STARS

$1-1-1998$

\title{
$540 \mathrm{~mW}$ of blue output power at $425 \mathrm{~nm}$ generated by intracavity frequency doubling an upconversion-pumped Er3+: YLiF4 laser
}

\author{
P. E. -A. Möbert \\ E. Heumann \\ G. Huber \\ B. H. T. Chai \\ University of Central Florida
}

Find similar works at: https://stars.library.ucf.edu/facultybib1990

University of Central Florida Libraries http://library.ucf.edu

This Article is brought to you for free and open access by the Faculty Bibliography at STARS. It has been accepted for inclusion in Faculty Bibliography 1990s by an authorized administrator of STARS. For more information, please contact STARS@ucf.edu.

\section{Recommended Citation}

Möbert, P. E. -A.; Heumann, E.; Huber, G.; and Chai, B. H. T., "540 mW of blue output power at $425 \mathrm{~nm}$ generated by intracavity frequency doubling an upconversion-pumped Er3+: YLiF4 laser" (1998). Faculty Bibliography 1990s. 2367.

https://stars.library.ucf.edu/facultybib1990/2367

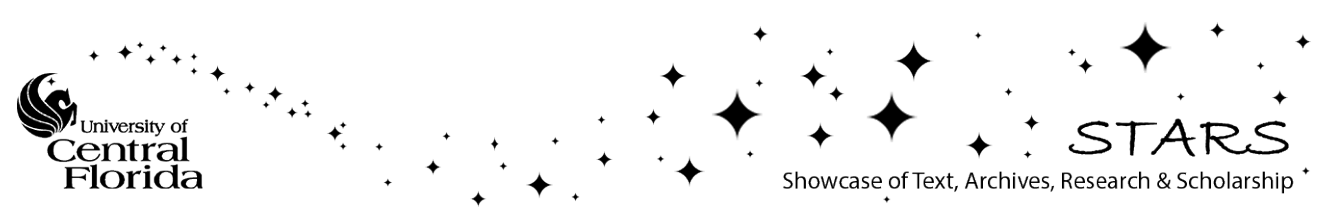




\section{$540 \mathrm{~mW}$ of blue output power at $425 \mathrm{~nm}$ generated by intracavity frequency doubling an upconversion-pumped $\mathrm{Er}^{3+}: \mathrm{YLiF}_{4}$ laser}

Cite as: Appl. Phys. Lett. 73, 139 (1998); https://doi.org/10.1063/1.121735

Submitted: 16 December 1997. Accepted: 13 May 1998. Published Online: 07 July 1998

P. E.-A. Möbert, E. Heumann, G. Huber, and B. H. T. Chai

\section{ARTICLES YOU MAY BE INTERESTED IN}

Threefold upconversion laser at $0.85,1.23$, and $1.73 \mu \mathrm{m}$ in Er:YLF pumped with a $1.53 \mu \mathrm{m} \mathrm{Er}$ glass laser

Applied Physics Letters 54, 869 (1989); https://doi.org/10.1063/1.100842

Green up-conversion laser emission in Er-doped crystals at room temperature Applied Physics Letters 63, 2030 (1993); https://doi.org/10.1063/1.110581

Green upconversion continuous wave $\mathrm{Er}^{3+}{ }^{+}$LiYF $_{4}$ laser at room temperature Applied Physics Letters 65, 383 (1994); https://doi.org/10.1063/1.112335
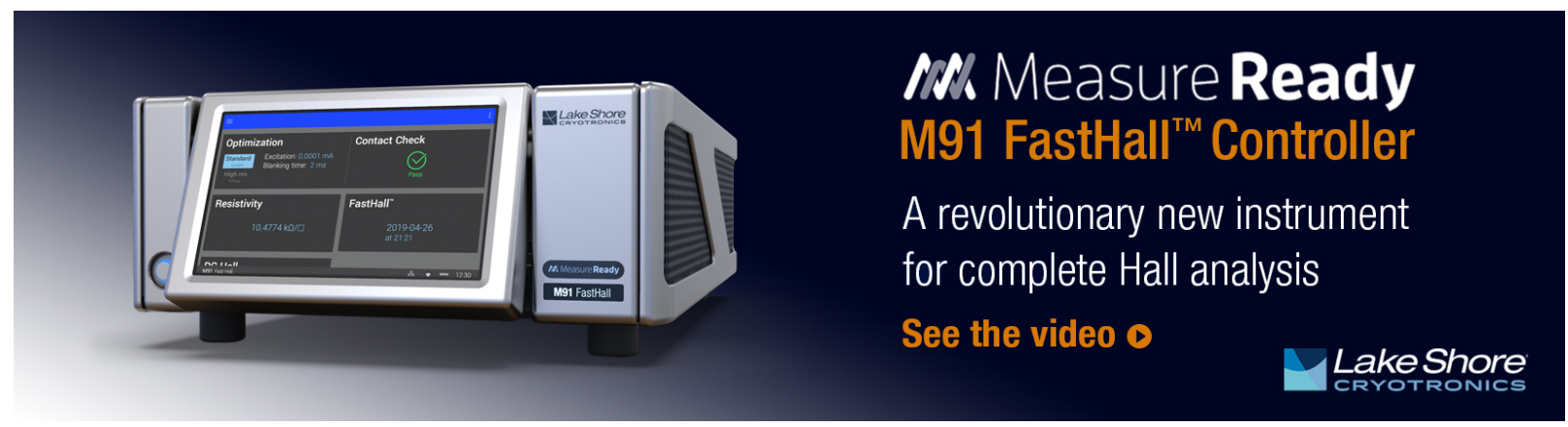

\section{曲 \\ View Online




\title{
$540 \mathrm{~mW}$ of blue output power at $425 \mathrm{~nm}$ generated by intracavity frequency doubling an upconversion-pumped $\mathrm{Er}^{3+}: \mathrm{YLiF}_{4}$ laser
}

\author{
P. E.-A. Möbert, ${ }^{\text {a) }}$ E. Heumann, and G. Huber \\ Institut für Laser-Physik, Universität Hamburg, Jungiusstrasse 9a, D-20355 Hamburg, Germany \\ B. H. T. Chai \\ Center for Research and Education in Optics and Lasers, University of Central Florida, Orlando, FL 32816
}

(Received 16 December 1997; accepted for publication 13 May 1998)

\begin{abstract}
We report efficient room-temperature continuous-wave intracavity frequency doubling of an upconversion-pumped $\operatorname{Er}(1 \%): \mathrm{YLiF}_{4}$ laser at $850 \mathrm{~nm}$. A titanium-sapphire laser was used for excitation of the ${ }^{4} S_{3 / 2} \rightarrow{ }^{4} I_{13 / 2}$ transition in erbium. The maximum laser output power at $850 \mathrm{~nm}$ was $1200 \mathrm{~mW}$. Intracavity frequency doubling the fundamental wave utilizing lithium triborate as nonlinear crystal yielded a maximum second-harmonic output power of $540 \mathrm{~mW}$ at $425 \mathrm{~nm}$. (C) 1998 American Institute of Physics. [S0003-6951(98)02728-4]
\end{abstract}

There has been an intense interest over the past few years in the development of compact all-solid-state lasers in the blue spectral range because of their potential application in optical data storage, printing facilities, and video display devices. Different approaches based on frequency doubling of infrared laser radiation either by birefringent phase matching or quasiphase matching in nonlinear crystals have been pursued so far to generate coherent continuous-wave $(\mathrm{cw})$ blue light: Direct frequency conversion of semiconductor laser diode radiation, ${ }^{1}$ intracavity ${ }^{2}$ and single-pass extracavity ${ }^{3}$ frequency doubling of laser light, and second-harmonic generation in an external resonant enhancement cavity. ${ }^{4}$ Sum frequency mixing, e.g., of two semiconductor laser diode beams, ${ }^{5}$ is another technique to obtain coherent blue light. Since continuous-wave blue conversion efficiencies in single-pass configurations have been suffered from rather low intensities of the fundamental wave, the highest cw blue output powers exceeding $500 \mathrm{~mW}$ have been attained by use of intracavity frequency doubling ${ }^{6}$ and external resonant enhancement cavities ${ }^{4}$ so far. However, the latter approach is restricted to certain applications due to the requirement of an active stabilization scheme.

Besides frequency doubling or sum frequency mixing of infrared laser transitions, upconversion lasers provide a solution to obtain radiation in the visible wavelength regime. The thulium-doped upconversion ZBLAN fiber laser at $480 \mathrm{~nm}$ is an example for a "simple" approach to realize a blue laser source. ${ }^{7-9}$ In general, upconversion lasers are operating with an emission wavelength shorter than the pump wavelength. ${ }^{10,11}$ Excitation of the active ions by interionic upconversion processes or intraionic excited-state absorption (ESA) processes results in the population of energy levels higher in energy than the pump photon energy. ${ }^{12}$ However, upconversion pumping can also be used to generate laser action between higher lying energy levels (especially in rareearth ions) where the emission wavelength is longer than the pump wavelength, e.g., the ${ }^{4} S_{3 / 2} \rightarrow{ }^{4} I_{11 / 2}$ transition in $\mathrm{Er}^{3+}: \mathrm{YLiF}_{4}(\mathrm{Er}: \mathrm{YLF})$ at $1.234 \mu \mathrm{m} .{ }^{13}$ Another example is the

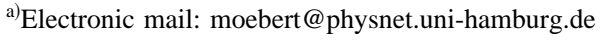

erbium ${ }^{4} S_{3 / 2} \rightarrow{ }^{4} I_{13 / 2}$ transition at $850 \mathrm{~nm}$ which is usually a self-terminating laser transition when ESA-pumped near 970 $\mathrm{nm}$ because of the long-lived lower laser level. ${ }^{14-16}$

In this letter we present efficient room-temperature $\mathrm{cw}$ operation of an ESA-pumped $\operatorname{Er}(1 \%): \mathrm{YLiF}_{4}$ laser on the ${ }^{4} S_{3 / 2} \rightarrow{ }^{4} I_{13 / 2}$ transition at $850 \mathrm{~nm}$ under Ti:sapphire laser excitation. The fundamental wave was intracavity frequencydoubled using lithium triborate (LBO) as nonlinear crystal to generate coherent $\mathrm{cw}$ blue light at $425 \mathrm{~nm}$.

A schematic illustration of the $\mathrm{Er}^{3+}$ ion energy-level diagram, depicted in Fig. 1, describes the excitation mechanism for the $850 \mathrm{~nm}$ laser transition. In a first step, erbium is excited into the ${ }^{4} I_{9 / 2}$ level by absorption of $792 \mathrm{~nm}$ pump photons. A nonradiative decay results in the population of the ${ }^{4} I_{13 / 2}$ level. A possible interionic cross relaxation $\left({ }^{4} I_{9 / 2},{ }^{4} I_{15 / 2}\right) \rightarrow\left({ }^{4} I_{13 / 2},{ }^{4} I_{13 / 2}\right)$ would populate additionally the ${ }^{4} I_{13 / 2}$ level but is rather unlikely due to the low $\mathrm{Er}^{3+}$ doping concentration of $1 \%$ and the short lifetime of the ${ }^{4} I_{9 / 2}$ level $(\tau=7 \mu \mathrm{s})$ which is the result of the high nonradiative decay rate into the ${ }^{4} I_{11 / 2}$ level. An excited-state absorption process ${ }^{4} I_{13 / 2} \rightarrow{ }^{2} H_{11 / 2}$ at $792 \mathrm{~nm}$ and a following nonradiative decay ${ }^{2} H_{11 / 2} \rightsquigarrow{ }^{4} S_{3 / 2}$ populates the upper laser level ${ }^{4} S_{3 / 2}$ of erbium. Simultaneously, the ESA process depopulates the long-lived

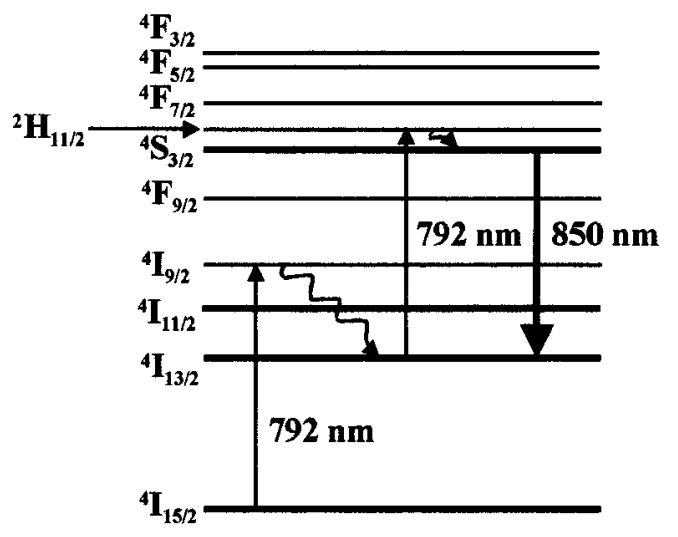

FIG. 1. Energy-level diagram for the $\mathrm{Er}^{3+}$ ion, depicting the two-step sequential absorption process exploited to populate the upper laser level. 


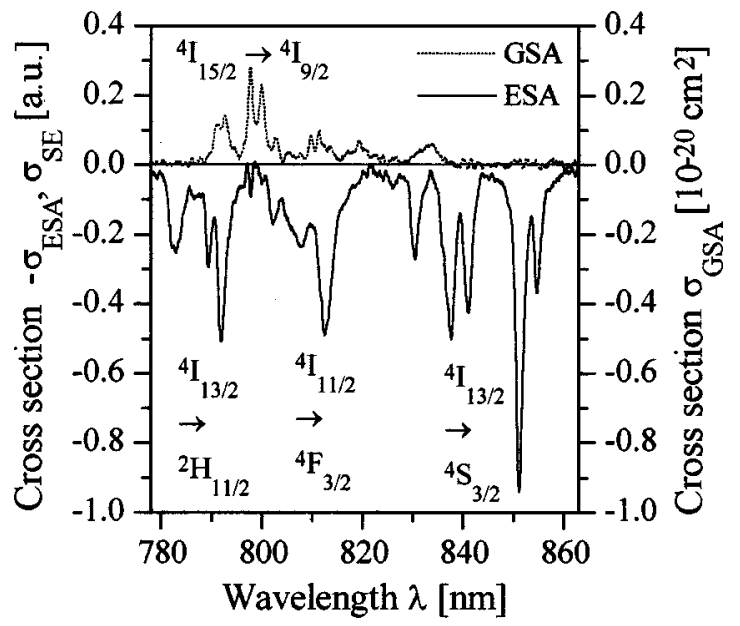

FIG. 2. Near infrared room-temperature $\mathrm{cw}$ excited-state absorption spectrum (ESA, solid line) of $\operatorname{Er}(1 \%): \mathrm{YLiF}_{4}$ compared with the ground-state absorption spectrum (GSA, dotted line).

lower laser level ${ }^{4} I_{13 / 2}$ and hence facilitates continuous-wave laser operation.

The excited-state absorption spectrum accounts for the experimentally determined pump wavelength of $792 \mathrm{~nm}$. The room-temperature cw ESA spectrum shown in Fig. 2 was measured by a pump and probe technique using an argon-ion laser at $514.5 \mathrm{~nm}$ as pump source and the light of a tungsten halogen lamp as probe beam. The transmitted intensity $I$ and the change in intensity of the pumped and unpumped crystal $\Delta I$ are detected simultaneously by a double modulation scheme. A positive signal in intensity $\Delta I$ is measured in spectral regions with ground-state absorption (due to a reduced population in the ground state) and stimulated emission (due to the population of excited states). Spectral regions with excited-state absorption cause a negative signal in intensity $\Delta I$. The ratio $\Delta I / I$ is proportional to the corresponding cross sections

$$
\frac{\Delta I}{I} \propto\left(\sigma_{\mathrm{GSA}}-\sum_{i} \frac{n_{i}}{n_{e}}\left(\sigma_{\mathrm{ESA}, i}-\sigma_{\mathrm{SE}, i}\right)\right) .
$$

The $\Delta I / I$ spectrum is calibrated by use of the ground-state absorption spectrum which is subtracted afterwards. The remaining spectrum comprises the stimulated emission $\sigma_{\mathrm{SE}}$ and excited-state absorption $\sigma_{\mathrm{ESA}}$ cross sections weighted with the population fractions $n_{i} / n_{e}$ of the corresponding excited states $\left(n_{e}=\Sigma n_{i}\right.$ is the density of all excited ions defined by the sum over the population densities $n_{i}$ of each excited state $i$ ). The determination of the absolute cross sections would require the knowledge of the relative population densities which are unknown. Hence it is only possible to make a qualitative analysis of the spectrum. A detailed description of the ESA measurement is given in Refs. 17 and 18. As already mentioned above, for continuous-wave laser operation it is essential to maintain the proper pump process ${ }^{4} I_{13 / 2} \rightarrow{ }^{2} H_{11 / 2}$ and thus depleting the ${ }^{4} I_{13 / 2}$ level. The upper laser level ${ }^{4} S_{3 / 2}$ and lower laser level ${ }^{4} I_{13 / 2}$ lifetimes for an $\mathrm{Er}^{3+}(1 \%)$ dopant concentration of $N=1.37 \times 10^{20} \mathrm{~cm}^{-3}$ in $\mathrm{YLiF}_{4}$ are $\tau=0.4$ and $10 \mathrm{~ms}$, respectively. Therefore the 850 $\mathrm{nm}$ laser transition is normally self-terminating when pumped via a different excitation scheme.

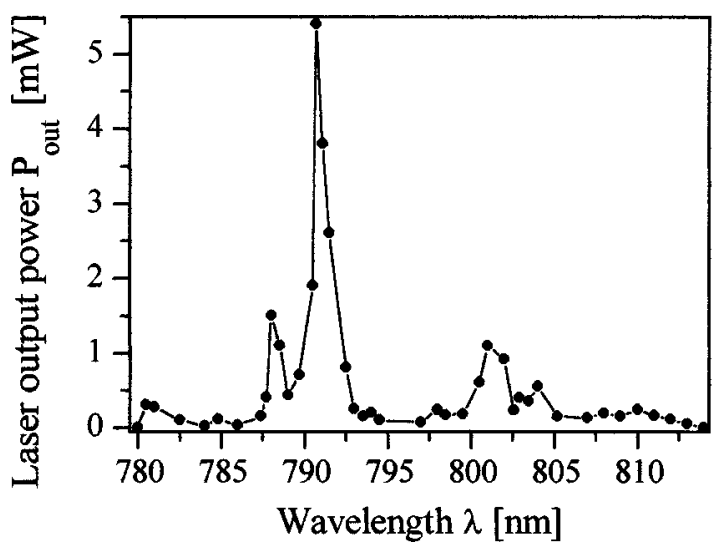

FIG. 3. Excitation spectrum of $\operatorname{Er}(1 \%): \mathrm{YLiF}_{4}$ showing the near infrared output power at $850 \mathrm{~nm}$ vs the Ti:sapphire pump wavelength (output coupling $T<0.01 \%$ at $850 \mathrm{~nm}, T>90 \%$ at $792 \mathrm{~nm}$ ).

The absorption cross section was measured to be $\sigma_{\mathrm{ABS}}=1 \times 10^{-21} \mathrm{~cm}^{2}$ at $792 \mathrm{~nm}$ (Fig. 2). The emission cross section $\sigma_{\mathrm{EMS}}=6.4 \times 10^{-20} \mathrm{~cm}^{2}$ at $850 \mathrm{~nm}$ was estimated from the known value of the ${ }^{4} S_{3 / 2} \rightarrow{ }^{4} I_{15 / 2}$ transition ${ }^{19}$ using the Füchtbauer-Ladenburg relation. ${ }^{20,21}$

In a first experiment an uncoated 6.5-mm-long $\operatorname{Er}(1 \%): \mathrm{YLiF}_{4}$ crystal was placed inside a nearly concentric cavity formed by two concave $R=-50 \mathrm{~mm}$ mirrors. The input mirror was coated to be high reflecting at the laser wavelength at $850 \mathrm{~nm}$ and high transmitting at the pump wavelength around $800 \mathrm{~nm}$. The transmission of the output coupler was $T=2.7 \%$ at $850 \mathrm{~nm}$ and greater than $90 \%$ at the pump wavelength. The Ti:sapphire laser was focused by an $f=50 \mathrm{~mm}$ focal length lens into the crystal. With this configuration we achieved a maximum cw laser output power of $P_{\text {out }}=765 \mathrm{~mW}$ at an input pump power level of $P_{\text {in }}=6 \mathrm{~W}$ which corresponds to a slope efficiency of $\eta_{s}=14.7 \%$. The absorbed pump power of the crystal was $P_{\text {abs }} / P_{\text {in }}=17 \%$, corresponding to a slope efficiency of $\eta_{s}=86.5 \%$ with respect to absorbed power. This value is greater than the theoretical quantum efficiency for a two-step absorption process which is $\eta_{q}=46.5 \%$ for a pump and laser wavelength of 792 and $850 \mathrm{~nm}$, respectively. However, because of the strong ESA process originating from the lower laser level and the laser transition terminating in the ${ }^{4} I_{13 / 2}$ level, this circulating mechanism can be considered as an isolated system with a single absorption process. The quantum limit for a single absorption process is $\eta_{q}=93 \% \quad\left(\lambda_{p}=792 \mathrm{~nm}, \quad \lambda_{l}\right.$ $=850 \mathrm{~nm})$. Actually, the laser results are very close to the quantum limit.

Infrared laser operation at $850 \mathrm{~nm}$ in $\mathrm{Er}_{\mathrm{YLiF}} \mathrm{YL}_{4}$ was obtained for different Ti:sapphire pump wavelengths. We measured the excitation spectrum (Fig. 3) near $792 \mathrm{~nm}$ in order to confirm the above stated two-step sequential absorption mechanism that populates the upper laser level ${ }^{4} S_{3 / 2}$. The tuning characteristic reflects the excited-state absorption ${ }^{4} I_{13 / 2} \rightarrow{ }^{2} H_{11 / 2}$ depicted in Fig. 2 and is a direct proof of the excitation process which enables continuous-wave laser operation. Five distinct peaks are recognizable in the spectrum of Fig. 3 which belong to the ${ }^{4} I_{13 / 2} \rightarrow{ }^{2} H_{11 / 2}$ excited-state absorption manifold. The maximum laser output power was obtained for a pump wavelength of $792 \mathrm{~nm}$ which is related to the maximum overlap between excited-state and groundstate absorption. 


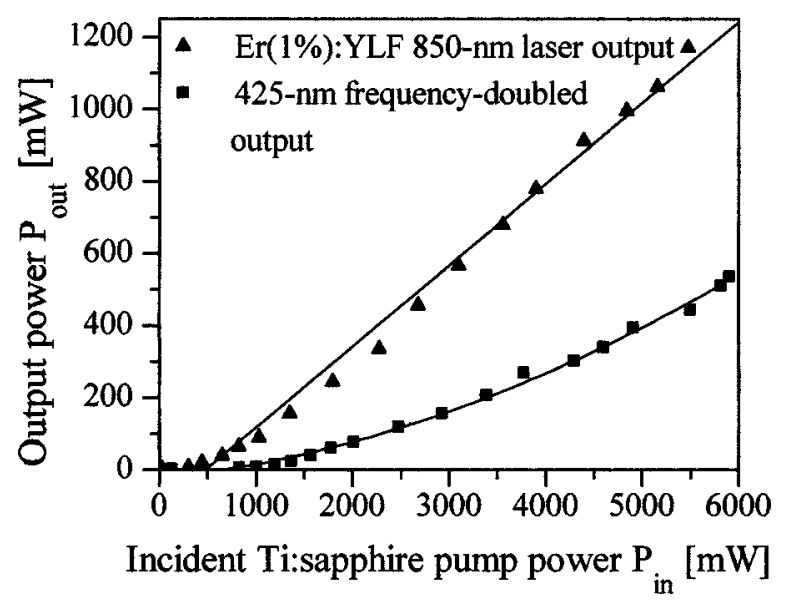

FIG. 4. $850 \mathrm{~nm}$ laser output power of $\operatorname{Er}(1 \%): \mathrm{YLiF}_{4}$ and second-harmonic output power at $425 \mathrm{~nm}$ as a function of the incident Ti:sapphire pump power.

In a second experiment we changed the concave output mirror to be high reflecting for the pump wavelength at 792 $\mathrm{nm}$ (radius of curvature $R=-100 \mathrm{~mm}$, output coupling $T$ $=7.1 \%$ at $850 \mathrm{~nm}$ ). The objective was to attain a resonant enhancement of the pump power, thereby increasing the absorbed pump power in the $\operatorname{Er}(1 \%): \mathrm{YLiF}_{4}$ crystal similar to a real intracavity experiment. We determined the actual pump enhancement by inserting a tilted glass plate into the pump beam and measuring the off axis reflected power. The ratio of the measured power with and without resonance at the pump wavelength yielded the resonant enhancement factor $\xi=2.2$. Utilizing this resonant pump configuration, we obtained a maximum $\mathrm{cw}$ laser output power of $P_{\text {out }}$ $=1200 \mathrm{~mW}$ at an evaluated Ti:sapphire pump power level of $P_{\mathrm{ev}}=5.5 \mathrm{~W} \times 2.2=12.1 \mathrm{~W}$. The laser output power at 850 $\mathrm{nm}$ as a function of the incident Ti:sapphire laser pump power is shown in Fig. 4.

For intracavity second-harmonic generation we chose a $l=10$-mm-long lithium triborate crystal $\left(\mathrm{LiB}_{3} \mathrm{O}_{5}, \mathrm{LBO}\right)$ as the nonlinear crystal cut for critical type I phase matching $\left(\theta=90^{\circ}, \phi=27^{\circ}\right.$, and $\left.d_{\text {eff }}=0.9 \mathrm{pm} / \mathrm{V}\right)$. LBO is a negative biaxial crystal. The fundamental wave was polarized parallel to the crystal $z$ axis, the second-harmonic wave was polarized in the $x-y$ plane. The experimental setup was the same as used for the previous experiments. The LBO crystal was placed close to the Er: $\mathrm{YLiF}_{4}$ crystal inside the cavity. The concave end mirror (radius of curvature $R=-100 \mathrm{~mm}$ ) was now coated to be high reflecting for the laser wavelength at $850 \mathrm{~nm}$, high transmitting for the pump wavelength at 792 $\mathrm{nm}$, and reflecting for the second-harmonic wavelength at $425 \mathrm{~nm}(T<5 \%)$. Therefore the concave input mirror was selected to be high transmitting at $425 \mathrm{~nm}$ (HR at $850 \mathrm{~nm}$, HT at $792 \mathrm{~nm}$ ) and hence used as output coupler for the blue radiation. In this configuration we attained a maximum $\mathrm{cw}$ blue output power of $P_{\text {out }}=106 \mathrm{~mW}$ at an incident Ti:sapphire laser pump power level of $P_{\text {in }}=5.9 \mathrm{~W}$.

When we changed the concave $-100 \mathrm{~mm}$ end mirror to be additionally high reflecting for the pump wavelength at $792 \mathrm{~nm}(T<5 \%$ at $425 \mathrm{~nm}, T<0.01 \%$ at $850 \mathrm{~nm})$ to obtain a resonant enhancement of the pump power in the cavity, we achieved a maximum cw $425 \mathrm{~nm}$ output power of $P_{\text {out }}$ $=540 \mathrm{~mW}$ at an incident Ti:sapphire pump power level of
$5.9 \mathrm{~W}$ (corresponding to an evaluated Ti:sapphire pump power of $\left.P_{\mathrm{ev}}=5.9 \mathrm{~W} \times 2.2=13 \mathrm{~W}\right)$. The input-output characteristic is shown in Fig. 4. The blue output power shows the significant quadratic dependence on the incident pump power. The threshold for blue light emission was at $P_{\mathrm{ev}}$ $=135 \mathrm{~mW} \times 2.2=270 \mathrm{~mW}$. The spot profile of the blue radiation was slightly elliptically which is attributed to the walk-off angle of $\rho=0.85^{\circ}$. The blue output was modulated by chaotic intensity fluctuations due to a nonlinear coupling of several longitudinal cavity modes. This phenomenon is known from the literature as "green problem", ${ }^{22}$ Experiments to reduce the intensity noise have not been performed yet.

In conclusion, efficient room-temperature continuouswave ESA-pumped lasing of Er:YLiF 4 at $850 \mathrm{~nm}$ was demonstrated. Utilizing a two-step sequential absorption mechanism, we achieved a maximum laser output power of 765 and $1200 \mathrm{~mW}$ in a nonresonant and resonant cavity configuration, respectively. Intracavity frequency doubling of the $850 \mathrm{~nm}$ transition yielded a second-harmonic output power of $106 \mathrm{~mW}(540 \mathrm{~mW})$ at $425 \mathrm{~nm}$ in a nonresonant (resonant) cavity arrangement.

Since room-temperature laser diode-pumped pulsed laser operation of the $850 \mathrm{~nm}$ transition in $\mathrm{Er}_{\mathrm{YLiF}} \mathrm{YL}_{4}$ was already demonstrated, ${ }^{23}$ future work will be focused on the development of an all-solid-state laser diode-pumped coherent blue light source at $425 \mathrm{~nm}$.

${ }^{1}$ D. Fluck, T. Pliska, and P. Günter, OSA Tops on ASSL 1, 365 (1996).

${ }^{2}$ G. Hollemann, E. Peik, and H. Walther, Opt. Lett. 19, 192 (1994); F. Hanson, Appl. Phys. Lett. 66, 3549 (1995).

${ }^{3}$ V. Pruneri, R. Koch, P. G. Kazansky, W. A. Clarkson, P. St. J. Russell, and D. C. Hanna, OSA Tops on ASSL 1, 42 (1996).

${ }^{4}$ M. Bode, I. Freitag, A. Tünnermann, and H. Welling, Opt. Lett. 22, 1220 (1997).

${ }^{5}$ D. Fluck and P. Günter, Opt. Commun. 136, 257 (1997).

${ }^{6}$ T. Kellner, F. Heine, and G. Huber, Appl. Phys. B: Laser Opt. 65, 789 (1997).

${ }^{7}$ S. Sanders, R. G. Waarts, D. G. Mehuys, and D. F. Welch, Appl. Phys. Lett. 67, 1815 (1995).

${ }^{8}$ H. Zellmer, S. Buteau, A. Tünnermann, and H. Welling, Electron. Lett. 33, 1383 (1997).

${ }^{9}$ R. Paschotta, N. Moore, W. A. Clarkson, A. C. Tropper, D. C. Hanna, and G. Maze, Conference on Lasers and Electro-Optics, Baltimore, Maryland, Technical Digest CTuG3 1997 (unpublished), p. 80.

${ }^{10}$ F. Heine, E. Heumann, T. Danger, T. Schweizer, G. Huber, and B. H. T. Chai, Appl. Phys. Lett. 65, 383 (1994).

${ }^{11}$ F. Heine, E. Heumann, P. Möbert, G. Huber, and B. H. T. Chai, OSA Proc. on ASSL 24, 74 (1995).

${ }^{12}$ F. Auzel, J. Lumin. 45, 341 (1990).

${ }^{13}$ E. Heumann, P. Möbert, and G. Huber, Exp. Tech. Phys. 42, 33 (1996).

${ }^{14}$ S. A. Pollack, D. B. Chang, and M. Birnbaum, Appl. Phys. Lett. 54, 869 (1989).

${ }^{15}$ C. A. Millar, M. C. Brierley, M. H. Hunt, and S. F. Carter, Electron. Lett. 26, 1871 (1990).

${ }^{16} \mathrm{P}$. Xie and S. Rand, Appl. Phys. Lett. 57, 1182 (1990).

${ }^{17}$ J. Koetke and G. Huber, Appl. Phys. B: Laser Opt. 61, 151 (1995).

${ }^{18}$ T. Danger, J. Koetke, R. Brede, E. Heumann, G. Huber, and B. H. T. Chai, J. Appl. Phys. 76, 1413 (1994).

${ }^{19}$ P. E.-A. Möbert, E. Heumann, G. Huber, and B. H. T. Chai, Opt. Lett. 22, 1412 (1997).

${ }^{20}$ D. E. McCumber, Phys. Rev. 136, 954 (1964).

${ }^{21}$ S. A. Payne, L. L. Chase, L. K. Smith, W. L. Kway, and W. F. Krupke, IEEE J. Quantum Electron. 28, 2619 (1992).

${ }^{22}$ T. Baer, J. Opt. Soc. Am. B 3, 1175 (1986).

${ }^{23}$ P. E.-A. Möbert, E. Heumann, G. Huber, and B. H. T. Chai, Conference on Advanced Solid-State Lasers, Coeur d' Alene, Idaho, Technical Digest, Paper No. AMA2 (1998). 